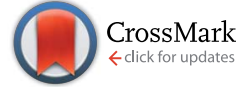

Cite this: RSC Adv., 2016, 6, 106081

Received 12th September 2016 Accepted 28th October 2016

DOI: $10.1039 / c 6 r a 22800 c$

\section{High performance stability of titania decorated carbon for desalination with capacitive deionization in oxygenated water $\uparrow$}

\author{
Pattarachai Srimuk, ${ }^{\text {ab }}$ Lucie Ries, $^{\text {ab }}$ Marco Zeiger, ${ }^{\text {ab }}$ Simon Fleischmann, ${ }^{\text {b }}$ \\ Nicolas Jäckel, ${ }^{a b}$ Aura Tolosa, ${ }^{\text {ab }}$ Benjamin Krüner, ${ }^{\text {ab }}$ Mesut Aslan ${ }^{a}$ \\ and Volker Presser ${ }^{\star a b}$
}

www.rsc.org/advances

Performance stability in capacitive deionization (CDI) is particularly challenging in systems with a high amount of dissolved oxygen due to rapid oxidation of the carbon anode and peroxide formation. For example, carbon electrodes show a fast performance decay, leading to just $15 \%$ of the initial performance after $50 \mathrm{CDI}$ cycles in oxygenated saline solution $(5 \mathrm{mM} \mathrm{NaCl})$. We present a novel strategy to overcome this severe limitation by employing nanocarbon particles hybridized with sol-gel-derived titania. In our proof-of-concept study, we demonstrate very stable performance in low molar saline electrolyte ( $5 \mathrm{mM} \mathrm{NaCl}$ ) with saturated oxygen for the carbon/metal oxide hybrid (90\% of the initial salt adsorption capacity after 100 cycles). The electrochemical analysis using a rotating disk electrode (RDE) confirms the oxygen reduction reaction (ORR) catalytic effect of $\mathrm{FW} 2 \mathrm{O0} / \mathrm{TiO}_{2}$, preventing local peroxide formation by locally modifying the oxygen reduction reaction.

\section{Introduction}

Capacitive deionization (CDI) is an emerging water treatment technology which is highly attractive for energy efficient removal of ions from aqueous media with low molar concentrations (especially below $100 \mathrm{mM}) \cdot{ }^{1-3}$ Common CDI operation accomplishes ion removal from a feed stream via capacitive ion electrosorption at the electrically charged fluid/solid interface between the electrolyte and the electrode. Most commonly, CDI employs nanoporous carbon, such as activated carbon, but also other carbons have been explored, for instance, graphene, carbon nanotubes, or carbide-derived carbon. ${ }^{4}$ During electrical charging of the carbon electrodes, ions are removed from the feed stream via electrosorption. ${ }^{5}$ A key value for CDI benchmarking is the desalination capacity (SAC $=$ salt adsorption

${ }^{a} I N M$ - Leibniz Institute for New Materials, Saarbrücken, Germany. E-mail: volker. presser@leibniz-inm.de

${ }^{b}$ Department of Materials Science and Engineering, Saarland University, Saarbrücken, Germany

$\dagger$ Electronic supplementary information (ESI) available. See DOI: $10.1039 / \mathrm{c} 6 \mathrm{ra} 22800 \mathrm{c}$ capacity), normalized to the electrode mass, and values of 15$21 \mathrm{mg} \mathrm{g}^{-1}$ have been reported..$^{6,7}$

CDI performance is commonly plagued by progressing degradation stemming from the electrochemical deterioration of the carbon electrodes. ${ }^{8-10}$ A challenge is the aggravating difference between the positively and negatively charged electrode: the former is continuously oxidized, leading to a shift in the electrode potential towards the oxygen reduction reaction (ORR) limit and enhanced degradation.9,11 One approach to mitigate the issue is the use of dissimilar electrodes. ${ }^{12,13}$ For example, modifying the carbon surfaces with functional groups allows to introduce an additional chemical charge and, effectively, shifts the point of zero charge of the respective electrodes. ${ }^{\mathbf{1 4 , 1 5}}$ By this way, CDI can even be completely inverted to yield ion release upon charging and desalination during discharging. Yet, the main focus of research on tuning carbon surface charge and functionality has remained on enhancing the salt removal capacity or the efficiency, but the longevity and performance stability remain widely unexplored. This is even more aggravated for practical, non-ideal systems, that is, aqueous saline media with dissolved oxygen, where $\mathrm{H}_{2} \mathrm{O}_{2}$ evolution occurs on the negatively polarized electrode..$^{16,17}$

Besides other metal oxides (like manganese oxide ${ }^{18}$ or zinc oxide $\left.{ }^{19}\right)$, titania/carbon hybrid materials have been investigated to enhance the desalination capacity ${ }^{20,21}$ and/or efficiency. ${ }^{22,23}$ These studies commonly cover the range of few desalination/ regeneration (charge/discharge) cycles, but even for CDI with just carbon electrodes, only few works show dozens or more cycles. ${ }^{8}$ So far, research has fallen short of investigating the potential for enhancing the CDI performance stability by use of metal oxide coatings.

In this study, we explore the hybridization of few-nanometersized carbon black particles (FW200) with titania via sol-gel synthesis and report on the remarkable performance stability in low molar saline media with a high amount of dissolved oxygen. We chose carbon black instead of microporous activated carbon because we wanted to avoid ion transport limitations within the network of nanopores in micrometer sized particles and to have 
access for titania decoration to an exclusive outer surface area. We also study the ORR catalyst ability of FW200 and FW200/ $\mathrm{TiO}_{2}$ to understand the origin of longevity performance in harsh (i.e., oxygenated) solution.

\section{Experimental}

\section{Material synthesis}

For our study, we used carbon black type FW200, which was purchased from Orion (formerly: Degussa) and used without further chemical treatment.

For $\mathrm{FW} 200 / \mathrm{TiO}_{2}$ synthesis, $18 \mathrm{~g}$ of vacuum dried carbon powder FW200 was dispersed in $200 \mathrm{~mL}$ ethanol and set on magnetic stirrer for $5 \mathrm{~h}$. Then, $16.1 \mathrm{~g}$ Ti(Iv) isopropoxide (Aldrich) was dissolved in $500 \mathrm{~mL}$ ethanol and set on magnetic stirrer which should give a carbon hybrid with 20 mass\% titania. During filling, the bottles/containers were purged with argon to avoid any moisture pick up from the environment. The Ti-isopropoxide solution and carbon slurry were poured together and stirred for further $48 \mathrm{~h}$ without any additional water for hydrolysis. After the surface functional groups of FW200 have reacted with Ti-isopropoxide, the slurry was centrifuged at $4000 \mathrm{rpm}$ for $1 \mathrm{~h}$ so that the excess of unreacted Ti-isopropoxide was removed. The sediment was dispersed in $500 \mathrm{~mL}$ ethanol and centrifuged and the supernatant was removed again. This procedure was repeated two times to remove the unreacted Ti-isopropoxide. The cleaned sediment was dried at $95{ }^{\circ} \mathrm{C}$ for $24 \mathrm{~h}$ and used for the electrode preparation.

\section{Structural and chemical characterization}

Scanning electron microscope (SEM) images were recorded with a JEOL JSM 7500F field emission scanning electron microscope operating at $3 \mathrm{kV}$. Energy dispersive X-ray spectroscopy (EDX) was carried out in the system with an X-Max silicon detector from Oxford Instruments using AZtec software for quantitative analysis. Transmission electron micrographs were taken with a JEOL 2100F transmission electron microscope at $200 \mathrm{kV}$. Powder samples were prepared by dispersing the powder in ethanol and drop casting them on a copper grid with lacey carbon film (Gatan).

Raman spectra were recorded with Renishaw inVia Raman microscope using a Nd-YAG laser with an excitation wavelength of $523 \mathrm{~nm}$. The spectral resolution was $1.2 \mathrm{~cm}^{-1}$ and the diameter of laser spot on the sample was $2 \mu \mathrm{m}$ with a power of $0.2 \mathrm{~mW}$. The spectra were recorded for $20 \mathrm{~s}$ and accumulation of 30-times to get high signal-noise and signal-background ratio.

X-ray diffraction (XRD) was conducted per use of a D8 Advance diffractometer (Bruker AXS) with a copper X-ray source $\left(\mathrm{Cu}_{\mathrm{K} \alpha}, 40 \mathrm{kV}, 49 \mathrm{~mA}\right)$ in point focus $(0.5 \mathrm{~mm})$ and a Goebel mirror. A VANTEC-500 (Bruker AXS) 2D detector was employed ( $25^{\circ}$ per step: measurement time $16.7 \mathrm{~min}$ per step). The sample was dispersed in ethanol and drop casted on a sapphire wafer and the sample holder was oscillating horizontally to enhance statistics with an amplitude of $5 \mathrm{~mm}$ with speed of $0.5 \mathrm{~mm} \mathrm{~s}^{-1}$ along the $x$ - and $0.2 \mathrm{~mm} \mathrm{~s}^{-1}$ along the $y$-axis.
Nitrogen gas sorption measurements at $-196{ }^{\circ} \mathrm{C}$ were carried out with an Autosorb system (Autosorb 6B, Quantachrome). The powder samples were outgassed at $250{ }^{\circ} \mathrm{C}$ for $10 \mathrm{~h}$ under vacuum conditions at $10^{2} \mathrm{~Pa}$ to remove adsorbed water; the outgassing temperature for film electrodes was $120{ }^{\circ} \mathrm{C}$. Nitrogen gas sorption was performed in liquid nitrogen in the relative pressure range from 0.008 to 1.0. The BrunauerEmmett-Teller specific surface area (BET-SSA) ${ }^{24}$ was calculated with the ASiQwin-software in the linear relative pressure range of 0.06-0.1. The density functional theory specific surface area (DFT-SSA) and pore size distribution were calculated via quenched-solid density functional theory ${ }^{25}$ assuming slitshaped pores.

Thermogravimetric analysis was carried out on dried hybrid samples at $10{ }^{\circ} \mathrm{C} \mathrm{min}^{-1}$ to $900{ }^{\circ} \mathrm{C}$ in flowing synthetic air $(20$ $\mathrm{cm}^{3} \min ^{-1}$ ) to determine the ash content, which corresponds to the total $\mathrm{TiO}_{2}$ content in the samples (TG 209F1, Netzsch).

\section{Electrode preparation}

All film electrodes were casted on graphite current collectors using a mixed PVP/PVB polymer binder. We had shown the stability of this binder system in aqueous $\mathrm{NaCl}$ solutions in a previous publication ${ }^{26}$ and the group of Likun Pan established CDI compatibility when using this binder in a recent study. ${ }^{27}$ The carbon hybrid slurry was prepared by dispersing $5 \mathrm{~g}$ of asprepared material and $128 \mathrm{mg}$ of polyvinylpyrrolidone (PVP) in $20 \mathrm{~g}$ of ethanol. After tip sonication for $10 \mathrm{~min}, 319 \mathrm{mg}$ of polyvinyl butyral (PVB; 25 mass\% in ethanol) was added and stirred for $30 \mathrm{~min}$. The solid content of pure carbon slurry was set to 10 mass\% to ensure castability. Afterwards, the slurry was casted on SGL graphite current collectors (250 $\mu \mathrm{m}$ thickness) and dried at $80{ }^{\circ} \mathrm{C}$ for $24 \mathrm{~h}$. The thickness of tape casted electrodes was $100 \mu \mathrm{m}$ for FW200 and $150 \mu \mathrm{m}$ and for $\mathrm{FW} 200 / \mathrm{TiO}_{2}$.

\section{Electrochemical measurements}

We prepared electrodes by using the same method as introduced for CDI electrodes. The slurry was drop casted on the graphite current collector. The as-prepared electrodes with a diameter of $10 \mathrm{~mm}$ were placed into our custom-build cell having spring loaded titanium pistons. A glass fiber mat (GF/A, Whatman) was used as a separator. $1 \mathrm{M} \mathrm{NaCl}$ was injected by vacuum backfilling. Electrochemical measurement was conducted with a VSP300 potentiostat/galvanostat (Bio-Logic). For the symmetric full-cell, cyclic voltammetry and galvanostatic cycling techniques were employed. The specific capacitance of the cell was calculated by using eqn (1):

$$
C_{\text {specific }}=\frac{1}{U m} \int_{t_{1}}^{t_{2}} I \mathrm{~d} t
$$

where, $I$ is the measurement current, $t_{2}-t_{1}$ is the discharge time, $U$ is the applied cell voltage (with respect to iR drop), and $m$ is mass of both electrodes.

To monitor the potential development of counter and working electrode in a two electrode setup, we introduced a Ag/ $\mathrm{AgCl}$ spectator reference electrode to the cell. During constant specific current of $0.1 \mathrm{~A} \mathrm{~g}^{-1}$ (charge/discharge), the cathode and 
anode potential were monitored by reference electrode and the different of potentials between cathode and anode were determined.

\section{Oxygen reduction reaction (ORR) evaluation}

A rotating disk electrode (RDE) was used to investigate ORR for FW200 and FW200/ $\mathrm{TiO}_{2}$. The RDE working electrode is a glassy carbon (GC) electrode (Bioanalytical Systems) with a diameter of $5 \mathrm{~mm}$. Prior to use, the RDE-GC was polished on pat with alumina powder slurry several times and dried at $60{ }^{\circ} \mathrm{C}$ for $6 \mathrm{~h}$. The carbon hybrid slurry was prepared by the following steps.

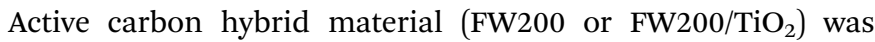
mixed with $2.5 \mathrm{mg}$ of PVP in $5 \mathrm{~mL}$ absolute ethanol. After that, $23 \mathrm{mg}$ of PVB solution (25 mass\% ethanol) was added to the previous mixture and stirred for $15 \mathrm{~min}$. The paste was drop casted on RDE-GC ( $3 \mu \mathrm{L}$ of slurry) and dried at $60^{\circ} \mathrm{C}$ for $2 \mathrm{~h}$. The as prepared RDE was connected to the RDE apparatus (RRDE3A, Bioanalytical Systems) having a Pt wire as counter electrode and $\mathrm{Ag} / \mathrm{AgCl}$ (saturated $\mathrm{KCl}$ ) as reference electrode. Prior to ORR analysis, $1 \mathrm{M} \mathrm{NaCl}$ was bubbled with $\mathrm{O}_{2}$ gas for $20 \mathrm{~min}$. Linear sweep voltammograms were applied at a sweep rate of $10 \mathrm{mV} \mathrm{s}^{-1}$ to investigate the ORR on both the FW200 and FW200/ $\mathrm{TiO}_{2}$ electrode. The working electrode potential was scanned from 0.2 to $-0.6 \mathrm{~V} v$ s. $\mathrm{Ag} / \mathrm{AgCl}$. The rotating speed was varied from $0 \mathrm{rpm}$ to $3200 \mathrm{rpm}$. To subtract the background capacitive current, $\mathrm{RDE}$ was tested in an $\mathrm{O}_{2}$-free solution at 0 rpm.

The Koutecky-Levich equation (eqn (2) and (3)) was used to estimate the number of electron transfers: ${ }^{28}$

$$
\begin{gathered}
\frac{1}{j}=\frac{1}{j_{\mathrm{K}}}+\frac{1}{j_{\mathrm{L}}}=\frac{1}{B} \omega^{-\frac{1}{2}}+\frac{1}{j_{\mathrm{K}}} \\
B=0.62 D^{\frac{2}{3}} \nu^{-\frac{1}{6}} n F C_{\mathrm{O}}
\end{gathered}
$$

with $j, j_{\mathrm{K}}$, and $j_{\mathrm{L}}$ being the measured, kinetic limited, and mass transfer limited current. Further, $D$ is the diffusion coefficient of dissolved oxygen in $1 \mathrm{M} \mathrm{NaCl}\left(2 \times 10^{-5} \mathrm{~cm}^{2} \mathrm{~s}^{-1}\right),{ }^{29} \nu$ is the kinetic viscosity of $1 \mathrm{M} \mathrm{NaCl}\left(0.0938 \mathrm{~cm}^{2} \mathrm{~s}^{-1}\right),{ }^{30} F$ is Faraday's constant (96 $485 \mathrm{C} \mathrm{mol}^{-1}$ ), $C_{\mathrm{O}}$ is the concentration of oxygen in $1 \mathrm{NaCl}$ at $25{ }^{\circ} \mathrm{C} 1 \mathrm{~atm}\left(2.59 \times 10^{-7} \mathrm{~mol} \mathrm{~cm}^{-3}\right),{ }^{31}$ and $n$ is the number of electron transfers involved in ORR. The parameter $j_{\mathrm{K}}$ is assumed to be constant after reaching equilibrium potential at one specific mass transfer condition $\left(j_{\mathrm{L}}\right)$. As shown in eqn (2), the measured current exhibits linear relation with $\omega^{-1 / 2}$; therefore, the inverse portion of $B$ indicates the slope of $\mathrm{K}-\mathrm{L}$ plot which allows the calculation of $n$ per use of eqn (3).

\section{CDI measurements}

The CDI setup described in ref. 32 with flow-by electrodes (per definition in ref. 1) was used to characterize the desalination performance. The CDI stack was built from the as prepared electrodes and a porous spacer (glass fiber pre-filter, Millipore, $380 \mu \mathrm{m}$ thickness). The measurements were carried out with three pairs of electrodes. Ion adsorption and desorption steps were carried out using constant potential mode at $1.2 \mathrm{~V}$. The electrode regeneration was accomplished at $0 \mathrm{~V}$. For all electrochemical operations, we used a VSP300 potentiostat/ galvanostat (Bio-Logic) and the duration of each half-cycle was $30 \mathrm{~min}$. All experiments were carried out with a flow rate of 22 $\mathrm{mL} \min ^{-1}$ of $5 \mathrm{mM} \mathrm{NaCl}$ solution and a $10 \mathrm{~L}$ electrolyte tank which was flushed continuously with $\mathrm{O}_{2}$ gas to ensure oxygen saturation. The salt adsorption capacity (SAC) and the measured charge were defined per mass of active material in both electrodes. For quantification of the electrical charge, the leakage current measured at the end of each half-cycle was subtracted.

\section{Results and discussion}

\section{Structural and chemical properties}

Carbon black type FW200 exhibits micrometer-sized aggregates (Fig. 1A and B), which consist of nanometer-sized primary particles of around 5-15 $\mathrm{nm}$ containing highly disordered carbon, as shown by transmission electron microscopy (Fig. 1C). The small size of the carbon black particles was intentionally chosen for providing facile access to the pore volume available for CDI operation and to minimize transport limitations due to impeded ion diffusion. The sol-gel synthesis of titania applied in our experiments yielded a homogenous hybridization of the carbon material (Fig. 1A), as can be seen from the elemental mapping of titanium (Fig. 1B). Quantitative analysis for the EDX spectra (Fig. 1D) yielded for FW200 $91 \pm 1$ mass \% carbon and $9 \pm 1$ mass $\%$ oxygen, and for $\mathrm{FW} 200 / \mathrm{TiO}_{2}$ a composition of $85 \pm 1$ mass $\%$ C, $13 \pm 1$ mass $\%$ O, and $2 \pm 1$ mass\% Ti. High resolution transmission electron microscopy revealed small clusters (ca. 1-2 nm) of titania (Fig. 1C, inset). The hybrid powder showed a mass loading of $c a .8$ mass $\%$ titania (=4.8 mass $\%$ titanium) as confirmed by thermogravimetric analysis (Fig. 1E). That value is larger than the amount of Ti determined by EDX ( 2 mass\%), because we have to consider the small spot size of the electron beam (effectively probing a small $\mu \mathrm{m}^{3}$ volume) and the thermogravimetric analysis is more representative for the total titanium mass in the sample. We see in the thermogram also an onset of the carbon oxidation at much lower temperatures for $\mathrm{FW} 200 / \mathrm{TiO}_{2}$ compared to just FW200. This is explained by the catalytic effect of the metal oxide on the carbon oxidation reaction. ${ }^{33}$

As seen from the Raman spectra (Fig. 1F), FW200 and FW200/ $\mathrm{TiO}_{2}$ display the typical pattern of carbon which consists of the D-band and the G-band at the wavelengths of about 1354 $\mathrm{cm}^{-1}$ and $1603 \mathrm{~cm}^{-1}$ and a distinct second order spectrum between 2200 and $3200 \mathrm{~cm}^{-1} \cdot{ }^{34}$ The spectra of FW200 and FW200/ $\mathrm{TiO}_{2}$ are virtually indistinguishable (Fig. 1F). We also did not observe any characteristic peaks of titania in FW200/ $\mathrm{TiO}_{2}$ since the domain size of titania (ca. $2 \mathrm{~nm}$; Fig. 1B) is too small to yield a detectable Raman signal. X-ray diffraction also shows only the presence of carbon per the peaks at $25.5^{\circ} 2 \theta$ and $42^{\circ} 2 \theta$, corresponding with the (002) and (110) reflections of graphitic carbon (Fig. 1G). This, too, is in alignment with the presence of few-nanometer-sized titania domains, scattered throughout the network of FW200 particles. 

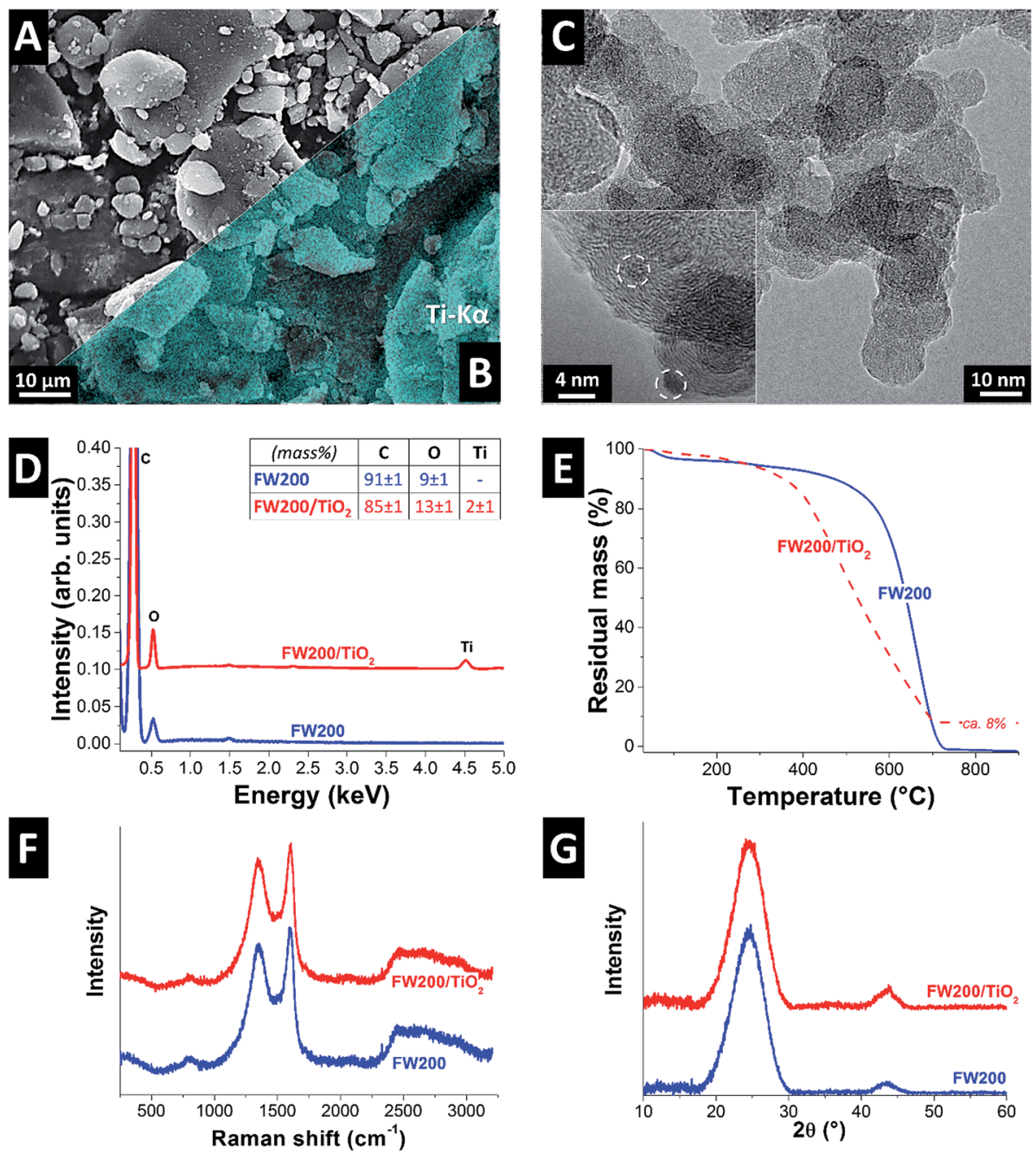

Fig. 1 (A) Scanning electron micrograph and (B) overlaid titanium chemical map (EDX) of hybrid FW200/TiO 2 . (C) Transmission electron micrographs of $\mathrm{FW} 200 / \mathrm{TiO}_{2}$ showing small titania domains. (D) EDX spectra of $\mathrm{FW} 200$ and $\mathrm{FW} 200 / \mathrm{TiO}_{2}$ along with quantitative data for C, O, and Ti. (E) Thermogravimetric analysis in synthetic air of FW200 and FW200/TiO 2. (F) Raman spectra and (G) X-ray diffractograms of FW200 and $\mathrm{FW} 200 / \mathrm{TiO}_{2}$.

Adding metal oxide to carbons may result in pore blocking of the electrode. ${ }^{35}$ By using small amounts of titania and small particles, we were able to limit porosity reduction (Fig. 2). In particular, we see a reduction of the DFT surface area from 549 $\mathrm{m}^{2} \mathrm{~g}^{-1}$ of FW200 to a value of $404 \mathrm{~m}^{2} \mathrm{~g}^{-1}$ for $\mathrm{FW} 200 / \mathrm{TiO}_{2}$ (i.e., $-27 \%$ ). This decrease can already be assessed from the nitrogen sorption isotherms (Fig. 2). Both isotherms are consistent with a material with interparticle nanopores like carbon onions. ${ }^{36}$ The measured surface areas align with the presence of pores just in-between the FW200 grains, with an ideal surface area of up to $545 \mathrm{~m}^{2} \mathrm{~g}^{-1}$ for non-porous carbon spheres of 5-15 nm diameter. Concluding from quenched solid density functional theory, the corresponding decrease in surface area is mostly accomplished by a decrease in micropores (i.e., pores below 2 $\mathrm{nm})$ as a result from certain pore blocking by titania nanodomains (Fig. 2B). The higher density of the metal oxide also contributes towards the reduction of surface area.

\section{Electrochemical characterization in high ionic strength}

The full-cell electrochemical measurements were carried out in oxygen free $1 \mathrm{M} \mathrm{NaCl}$ solution to investigate the charge adsorption capability of FW200 and $\mathrm{FW} 200 / \mathrm{TiO}_{2}$. As seen in Fig. 3A, the cyclic voltammograms of FW200 and its composite at $5 \mathrm{mV} \mathrm{s}^{-1}$ exhibit rectangular shape, indicative of charge storage predominately accomplished by double-layer formation (i.e., ion electrosorption). ${ }^{37}$ The same is indicated by the pronouncedly triangular shape of galvanostatic chargedischarge plots (Fig. 3B). The specific capacitance of FW200 and $\mathrm{FW} 200 / \mathrm{TiO}_{2}$ at low specific current of $0.1 \mathrm{~A} \mathrm{~g}^{-1}$ is $112 \mathrm{~F} \mathrm{~g}^{-1}$ and $101 \mathrm{~F} \mathrm{~g}^{-1}$, respectively, while the specific capacitance at high specific current of $10 \mathrm{~A} \mathrm{~g}^{-1}$ is $43 \mathrm{~F} \mathrm{~g}^{-1}$ for FW200 and $47 \mathrm{~F} \mathrm{~g}^{-1}$ for $\mathrm{FW} 200 / \mathrm{TiO}_{2}$, respectively (Fig. 3C). The lower specific surface area of $\mathrm{FW} 200 / \mathrm{TiO}_{2}$ accounts for the lower specific capacitance, although the difference is much less as might be indicated from the $27 \%$ lower accessible surface area compared to FW200. 

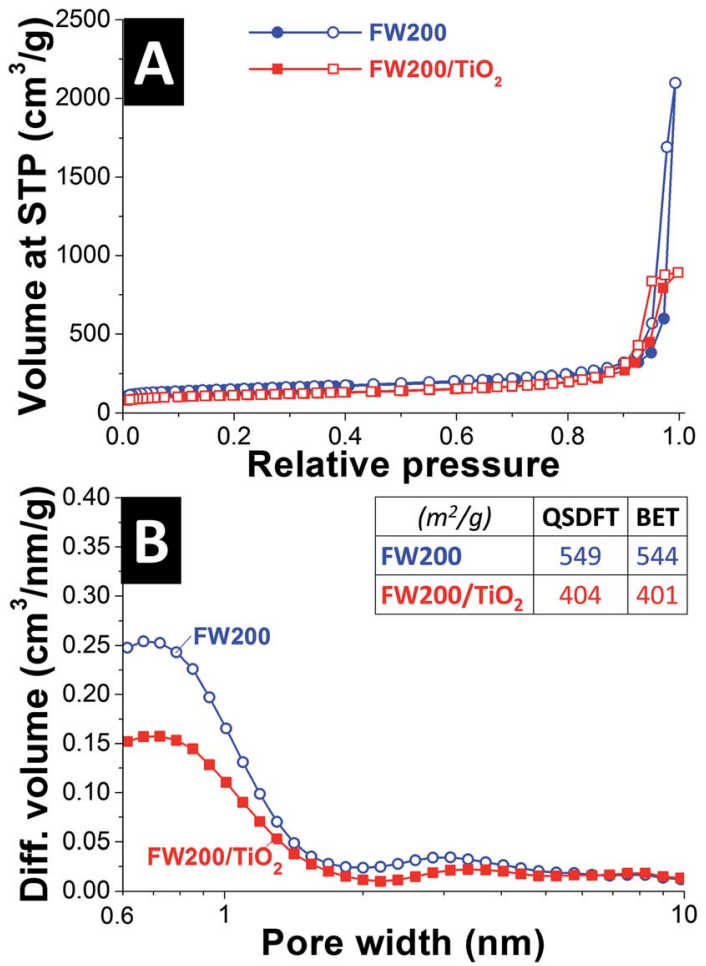

Fig. 2 (A) Nitrogen gas sorption isotherm of $\mathrm{FW} 200$ and $\mathrm{FW} 200 / \mathrm{TiO}_{2}$ showing pore blocking for the latter. (B) Differential pore size distribution calculated via quenched solid density functional theory assuming slit-shaped pores for FW200 and FW200/ $\mathrm{TiO}_{2}$ showing the mixed micro-mesoporous nature of both materials.
The potential development of cathode and anode in the fullcell was benchmarked by introducing an $\mathrm{Ag} / \mathrm{AgCl}$ spectator electrode (Fig. 3D). The zero charge potentials $\left(E_{0}\right)$ of FW200 and $\mathrm{FW} 200 / \mathrm{TiO}_{2}$ are shifted to positive values $v s$. $\mathrm{Ag} / \mathrm{AgCl}$ at all studied cell voltages (i.e., between $0.6 \mathrm{~V}$ and $1.4 \mathrm{~V}$ ). This implies the influence of negatively charged surface groups which get neutralized by cations, leading to an asymmetric potential distribution between cathode $\left(\Delta E_{\text {cathode }}=0.64 \mathrm{~V} v s\right.$. Ag/AgCl at cell voltage of $1.2 \mathrm{~V})$ and anode $\left(\Delta E_{\text {anode }}=-0.56 \mathrm{~V} v s . \mathrm{Ag} / \mathrm{AgCl}\right.$ at cell voltage of $1.2 \mathrm{~V}$ ). Nanodecoration with titania further shifts the potentials to positive values of $\Delta 80 \mathrm{mV}$ at $0.6 \mathrm{~V}$ cell voltages; yet, the differences gradually reduce and virtually vanish at $1.4 \mathrm{~V}$.

\section{Capacitive deionization performance}

The desalination performance of $\mathrm{FW} 200$ and $\mathrm{FW} 200 / \mathrm{TiO}_{2}$ was measured at $1.2 \mathrm{~V}$ cell voltage, using a symmetrical twoelectrode setup and aqueous $5 \mathrm{mM} \mathrm{NaCl}$ saline solution. We bubbled the electrolyte with $\mathrm{O}_{2}$ to achieve oxygen saturation. This is in stark contrast to the majority of work in the CDI literature, where, with some exceptions (e.g., ref. 38), mostly deaerated saline media are investigated., ${ }^{1,2}$ FW200 carbon electrodes required 35 CDI cycles (i.e., charging and discharging cycles) to achieve equilibrium performance, that is, to obtain the same salt adsorption and salt desorption capacity. Only after such equilibrium is reached, meaningful values for the salt adsorption capacity (SAC) can be obtained and compared to literature. ${ }^{1}$ During the 35 conditioning cycles, there were strong fluctuations of the online monitored conductivity of the outflowing saline solution. We even observed, limited to the early
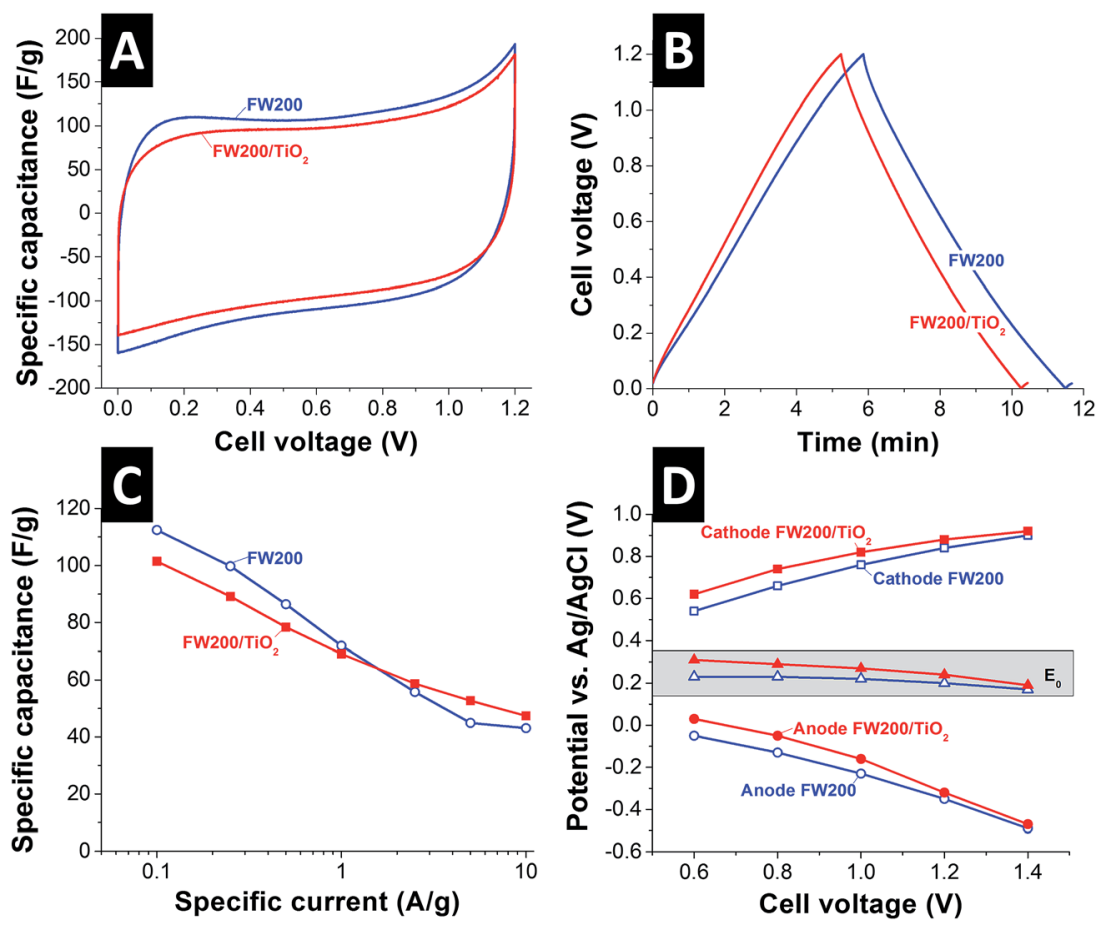

Fig. 3 (A) Cyclic voltammograms at $5 \mathrm{mV} \mathrm{s}^{-1}$, (B) galvanostatic charge-discharge curve at $0.1 \mathrm{~A} \mathrm{~g}^{-1}$, (C) rate capability, and (D) cathode, anode and zero charge potential monitoring along with different cell voltages. 

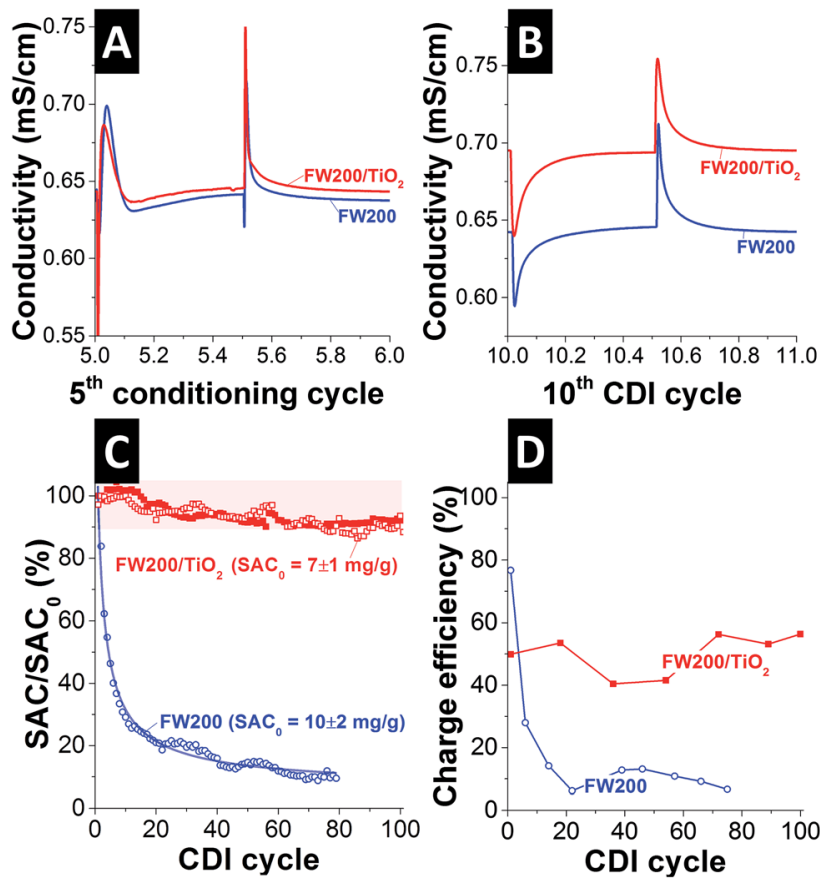

Fig. 4 (A) Typical conductivity curve for a conditioning cycle (shown data for the 5th conditioning cycle) with inverted CDI operation during the desorption cycle (1st half cycle). (B) Typical conductivity curve for conditioned CDI operation (shown data for the 10th CDI cycle) with regular ad- and desorption half-cycles. (C) Salt adsorption capacity (SAC) performance normalized to the first-cycle CDI cycle. The solid lines are fits for an exponential decay (blue; for FW200). For FW200/ $\mathrm{TiO}_{2}$, two data sets of individual CDI cells are presented. (D) Charge efficiency values corresponding with the data shown in panel (C).

cycles during conditions, evidence of $\mathrm{CDI}$ inversion, where ions are desorbed during charging (Fig. 4A)., ${ }^{9,10,38}$ These high fluctuations are a result of the nanoscopic size of the carbon black primary particles and the obvious reactivity with surface functional groups, which are evidenced by an oxygen content of 9 mass\% in FW200, as measured by EDX. After the initial conditioning, conventional CDI adsorption/desorption cycles occurred for FW200, as depicted in Fig. 4B (highlighting the 10th CDI cycle). Prolonged operation of FW200, however, lead to a gradual decrease of the SAC values. Starting from $10 \pm 2 \mathrm{mg}$ $\mathrm{g}^{-1}$ for the first CDI cycle (averaged over two experiments), the performance decrease follows almost an exponential law and fades by $80 \%$ to $c a$. $2 \mathrm{mg} \mathrm{g}^{-1}$ after 20 CDI cycles and by $90 \%$ to $\sim 1 \mathrm{mg} \mathrm{g}^{-1}$ after 60 CDI cycles.

In case of $\mathrm{FW} 200 / \mathrm{TiO}_{2}$, we also observed an initial conditioning phase of 35 cycles (Fig. 4A), following the same pattern as FW200 (Fig. 4B). Obviously, the run-in behavior is dominated by the majority phase (i.e., FW200 $=92$ mass\%) and its surface chemistry. Yet, the initial SAC of the first CDI cycle (i.e., after conditioning) of $7 \pm 1 \mathrm{mg} \mathrm{g}^{-1}$ (averaged over three experiments) reduces by only $c a$. $10 \%$ after $100 \mathrm{CDI}$ cycles (Fig. 4C). To the best of our knowledge, this is by far the highest performance stability for any CDI system reported so far for oxygen-saturated saline electrolyte without the use of membranes. We also highlight that we used a cell voltage of $1.2 \mathrm{~V}$, instead of a lower voltage, as surveyed for example in ref. 9. The latter reference illustrates the benefit in performance stability when reducing the cell voltage, for example, from $0.9 \mathrm{~V}$ to $0.7 \mathrm{~V}$. The observed performance stability enhancement is clearly linked with the presence of titania. When using standard carbon materials, dissolved oxygen is reduced and consumed to form $\mathrm{H}_{2} \mathrm{O}_{2}$ as the major reagent during CDI. ${ }^{39}$ Once $\mathrm{H}_{2} \mathrm{O}_{2}$ is formed, the oxidation of carbon is boosted and this leads to severe degradation of the carbon electrode material. ${ }^{16,17}$ The mechanism for oxygen reduction reaction over carbon material in alkaline media has been reported elsewhere. ${ }^{40}$

Charge efficiency, the ratio between invested charge and removed ions, is a useful tool to further characterize CDI performance and stability. ${ }^{41}$ As can be seen from Fig. $4 \mathrm{D}$, the initial charge efficiency for FW200 is high with $c a$. $80 \%$, but drops to $c a$. $10 \%$ after 20 cycles. This aligns with the fast decay in SAC, as seen in Fig. 4C, and low values for the charge efficiency are common for carbons with a high heteroatom content in the form of surface functionalities. ${ }^{42}$ The titania decorated hybrid electrode displays a lower, but much more stable charge efficiency with an average value of $50 \pm 6 \%$ over 100 cycles (Fig. 4D). The lower value may result from some amounts of transferred charge that is contributing to the modified ORR process and, hence, is not contributing to the actual salt removal.

The CDI evaluation of $\mathrm{FW} 200$ and $\mathrm{FW} 200 / \mathrm{TiO}_{2}$ in de-aerated $5 \mathrm{mM} \mathrm{NaCl}$ (i.e., the typical electrolyte used for most CDI work) is shown in Fig. 5. At first, FW200 displays a small inverse peak before starting the adsorption process again (Fig. 5A), but after 15 cycles, the inverse peak vanished (Fig. 5B). The decrease of the inverse peak may be linked to progressing carbon oxidation at the positive electrode. In contrast, $\mathrm{FW} 200 / \mathrm{TiO}_{2}$ exhibits rather constant inverse peaks (Fig. 5A and $\mathrm{B}$ ). The salt adsorption performance of $\mathrm{FW} 200$ and $\mathrm{FW} 200 / \mathrm{TiO}_{2}$ is shown in Fig. 5C. The SAC of FW200 and $\mathrm{FW} 200 / \mathrm{TiO}_{2}$ starts at $5.5 \mathrm{mg} \mathrm{g}^{-1}$ and slightly decays before stabilizing around $2 \mathrm{mg} \mathrm{g}^{-1}$ after 20 CDI cycles. Thus, the SAC performance in de-aerated aqueous solution is rather similar for $\mathrm{FW} 200$ and $\mathrm{FW} 200 / \mathrm{TiO}_{2}$, leading to an unfavorable decay in performance of more than $50 \%$ of the initial value over just 10 cycles. Partially inverted CDI also leads to an unfavorably low charge efficiency of $20-30 \%$ after 20 CDI cycles (Fig. 5D). Considering these performance values, FW200, with or without titania decoration, is unfavorable for use in deaerated aqueous solution. Seemingly, the majority phase (FW200) and its associated surface functionalities dominate the electrochemical performance in de-aerated solutions, exhibiting low charge efficiency and fast decay of SAC performance.

For comparison, we synthesized activated carbon/titania hybrids by using the same method as $\mathrm{FW} 200 / \mathrm{TiO}_{2}$ and tested the CDI performance in oxygen saturated $5 \mathrm{mM} \mathrm{NaCl}$. We chose commercial YP-80F (Kuraray) with a BET surface area of 2347 $\mathrm{m}^{2} \mathrm{~g}^{-1}$, which is characterized by a large inner porosity. ${ }^{43}$ As shown in Fig. S1 (ESI $\dagger$ ), pristine activated carbon exhibits a SAC of $9 \mathrm{mg} \mathrm{g}^{-1}$ in the first cycle and a drastic decrease to nearly zero after 15 cycles. This fading in CDI performance of pure activated carbon is related to the oxidization of the anode, comparable to what we have shown for FW200. Once titania is coated on the activated carbon surface, the prolongation of CDI performance 

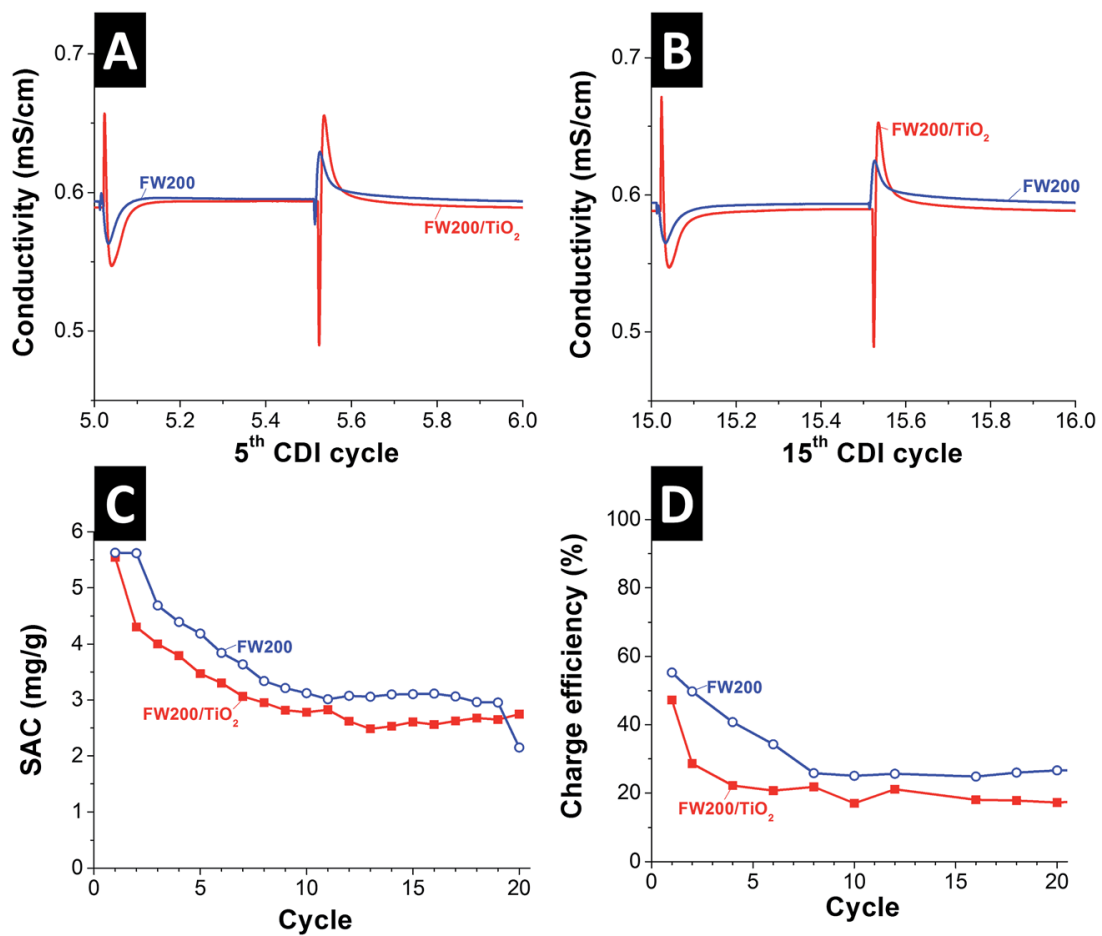

Fig. $5 \mathrm{CDI}$ performance of $\mathrm{FW} 200$ and $\mathrm{FW}_{200 / T i \mathrm{O}_{2}}$ in de-aerated $5 \mathrm{mM} \mathrm{NaCl}$ with $22 \mathrm{~mL} \mathrm{~min} \mathrm{~m}^{-1}$ of flow rate. The applied cell voltage is $1.2 \mathrm{~V}$ during charging and $\mathrm{OV}$ during discharging. (A and B) Conductivity at 5th and 15th cycle. (C) Salt adsorption capacity over 30 cycles. (D) Charge efficiency corresponds to the data shown in panel (C).

in oxygen saturated solution can be seen. The activated carbon/ titania hybrid shows a very high initial SAC of $18 \mathrm{mg} \mathrm{g}^{-1}$ in the first cycle, but decreases to a rather constant value of $c a .2 \mathrm{mg}$ $\mathrm{g}^{-1}$ after 60 cycles. Thus, while titania nanodecoration of activated carbon seemingly improves the performance and CDI stability, the improvement is inferior to what is seen for FW200/ $\mathrm{TiO}_{2}$, where the majority of surface area is associated with outer surface.

We further studied the catalytic activity (ORR) of titania decoration on FW200 by use of a rotating ring electrode (RDE). As shown in Fig. 6A, linear sweep voltammograms at $10 \mathrm{mV} \mathrm{s}^{-1}$ and $0 \mathrm{rpm}$ of $\mathrm{FW} 200$ and $\mathrm{FW} 200 / \mathrm{TiO}_{2}$ exhibit an ORR onset potential of $-0.086 \mathrm{~V}$ and $0.049 \mathrm{~V} v s$. $\mathrm{Ag} / \mathrm{AgCl}$, respectively. The higher onset potential of $\mathrm{FW} 200 / \mathrm{TiO}_{2}$ implies that titania catalyzes ORR. To obtain further information about ORR including the influence of mass diffusion on ORR, RDE measurements with various rotating speeds (200-3200 rpm) were carried out (Fig. 6A and B). For FW200 and FW200/TiO the diffusion current $\left(i_{\mathrm{L}}\right)$ is increased when increasing the rotation speed due to the reduction of diffusion length. The measured current at $-0.3 \mathrm{~V} v s$. $\mathrm{Ag} / \mathrm{AgCl}$ of FW200 and FW200/ $\mathrm{TiO}_{2}$ shows a rather linear correlation with the square root of the rotation speed. The resulting slope of the K-L plot (Fig. 6D) according to eqn (2) and (3) reflects the mechanism by the estimation of $n$. As shown in Fig. 6D, FW200 presents 1.4 electron transfers, while $\mathrm{FW} 200 / \mathrm{TiO}_{2}$ displays a four electron transfer. As identified in eqn (4)-(6), the four electron transfer (eqn (4)) is favorable for CDI longevity because only hydroxyl ions are formed as reactants. However, in our case, the four electron pathway is not preferred when carbon has a high amount of oxygen functional groups ( 9 mass\%). Earlier work has shown that oxygen functional groups including carbonyl, carboxyl, and hydroxyl dangling bonds on carbon nanotubes exhibit a two electron pathway at a potential of $-0.6 \mathrm{~V} v s$. Ag/ $\mathrm{AgCl}$ with an onset potential of $c a .-0.1 \mathrm{~V} v s$. $\mathrm{Ag} / \mathrm{AgCl} .{ }^{44}$ Therefore, the results shown in the inserted table in Fig. 6D are in good alignment with previous work, since FW200 exhibits 1.4 electron transfers leading to hydrogen peroxide formation (eqn (5)).

$$
\begin{gathered}
\mathrm{O}_{2}+2 \mathrm{H}_{2} \mathrm{O}+4 \mathrm{e}^{-} \rightarrow 4 \mathrm{OH}^{-} \\
\mathrm{O}_{2}+\mathrm{H}_{2} \mathrm{O}+2 \mathrm{e}^{-} \rightarrow \mathrm{HO}_{2}^{-}+\mathrm{OH}^{-} \\
\mathrm{HO}_{2}^{-}+\mathrm{H}_{2} \mathrm{O}+2 \mathrm{e}^{-} \rightarrow 3 \mathrm{OH}^{-}
\end{gathered}
$$

We expect initial $\mathrm{H}_{2} \mathrm{O}_{2}$ is further reduced on $\mathrm{FW} 200 / \mathrm{TiO}_{2}$. The latter has the catalytic ability to modify the oxygen reduction reaction, reducing $\mathrm{H}_{2} \mathrm{O}_{2}$ to hydroxide (eqn (6)), ${ }^{45}$ as enabled by the four electron transfer in $\mathrm{FW} 200 / \mathrm{TiO}_{2}$ (inserted table in Fig. 6D). The observed CDI behavior is explained by a transition of the two electron transfer reaction for FW200 that leads to peroxide formation, to a four electron transfer reaction for $\mathrm{FW} 200 / \mathrm{TiO}_{2}$, thereby further reducing peroxide evolution and effectively preventing the oxidative carbon degradation. This explanation requires more comprehensive follow-up work to further elucidate the 

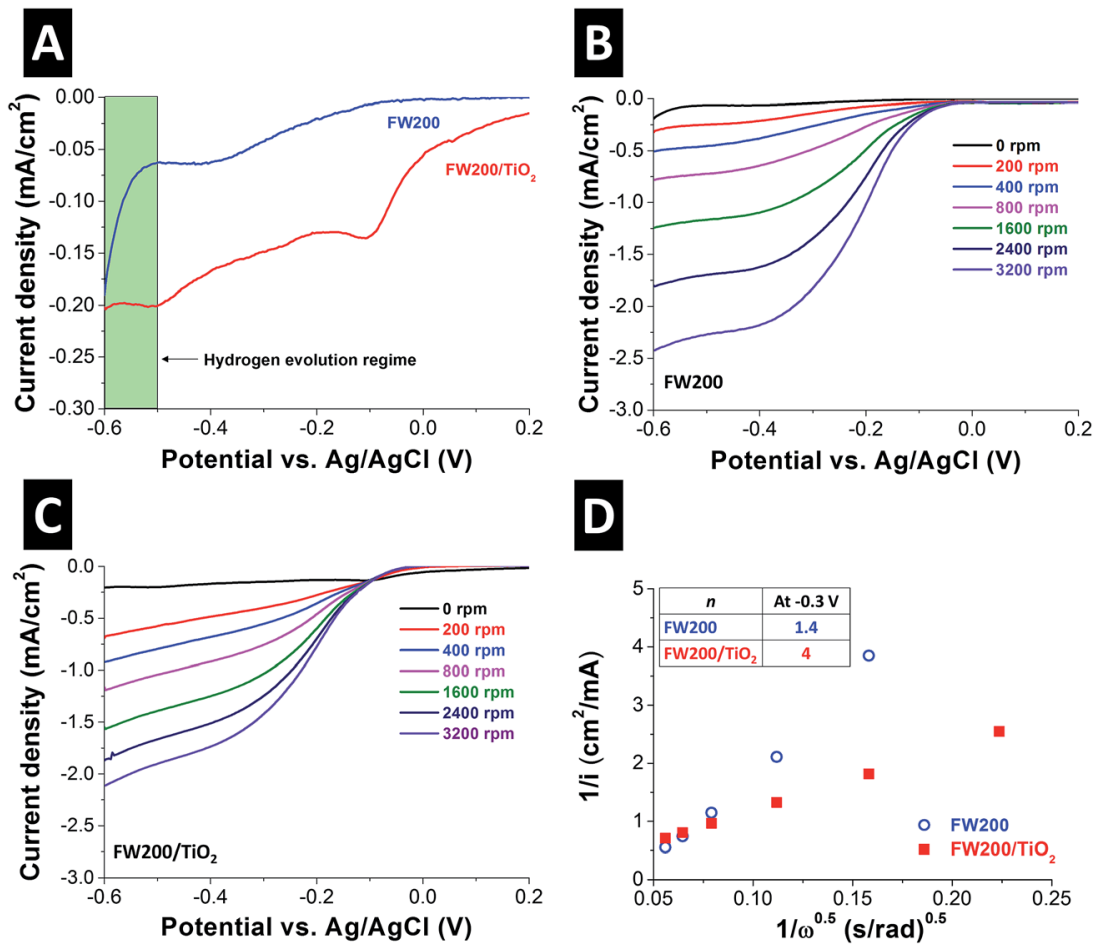

Fig. 6 (A) Linear sweep voltammograms (LSV) at $10 \mathrm{mV} \mathrm{s}^{-1}$ of $\mathrm{FW} 200$ and $\mathrm{FW} 200 / \mathrm{TiO}_{2}$ in oxygen saturated $1 \mathrm{M} \mathrm{NaCl}$ at 0 rpm, (B and C) LSV at $10 \mathrm{mV} \mathrm{s}^{-1}$ of $\mathrm{FW} 200$ (B) and $\mathrm{FW} 200 / \mathrm{TiO}_{2}$ (C) in $\mathrm{O}_{2}$ saturated $1 \mathrm{M} \mathrm{NaCl}$ with various rotation speeds, and (D) Koutecky-Levich (K-L) plot at -0.3 V vs. $\mathrm{Ag} / \mathrm{AgCl}$.

precise mechanisms behind this intriguing performance stability. In absence of excess oxygen, in de-aerated water, ORR does not occur and the carbon degeneration per surface functional groups seemingly dominates the decay of the CDI performance.

\section{Conclusions}

The titania decoration of carbon proved to be an excellent and facile approach to overcome the limited CDI performance stability in oxygen saturated saline solutions. Starting with a promising SAC value of $10 \mathrm{mg} \mathrm{g}^{-1}$, carbon black shows a negligible salt removal capacity of $2 \mathrm{mg} \mathrm{g}^{-1}$ after just 20 CDI cycles. Titania-decorated carbon black showed a stable performance of $7 \pm 1 \mathrm{mg} \mathrm{g}^{-1}$ over a remarkable duration of $100 \mathrm{CDI}$ cycles, being by far the most stable CDI system not using membranes in oxygen saturated media. Future work beyond this proof-of-concept study will have to establish the exact mechanism behind this intriguing performance stability and find the optimized amount of titania loading, while extending the scope to other carbon materials.

\section{Acknowledgements}

This work was carried out within the framework of the FrancoGerman EEIGM Master's Program in Materials Science at Saarland University. S. P. acknowledges financial support by the German Academic Exchange Service (DAAD award number
91579066). The authors thank Prof. Eduard Arzt (INM) for his continuing support.

\section{References}

1 M. E. Suss, S. Porada, X. Sun, P. M. Biesheuvel, J. Yoon and V. Presser, Energy Environ. Sci., 2015, 8, 2296-2319.

2 S. Porada, R. Zhao, A. van der Wal, V. Presser and P. M. Biesheuvel, Prog. Mater. Sci., 2013, 58, 1388-1442.

3 J. W. Blair and G. W. Murphy, in Saline Water Conversion, American Chemical Society, 1960, vol. 27, ch. 20, pp. 206-223.

4 Y. Liu, C. Y. Nie, X. J. Liu, X. T. Xu, Z. Sun and L. K. Pan, RSC $A d v .$, 2015, 5, 15205-15225.

5 T. Kim, J. E. Dykstra, S. Porada, A. van der Wal, J. Yoon and P. M. Biesheuvel, J. Colloid Interface Sci., 2015, 446, 317-326.

6 X. Xu, L. Pan, Y. Liu, T. Lu, Z. Sun and D. H. C. Chua, Sci. Rep., 2015, 5, 8458.

7 X. Xu, Z. Sun, D. H. C. Chua and L. Pan, Sci. Rep., 2015, 5, 11225.

8 X. Gao, A. Omosebi, J. Landon and K. L. Liu, Energy Environ. Sci., 2015, 8, 897-909.

9 I. Cohen, E. Avraham, Y. Bouhadana, A. Soffer and D. Aurbach, Electrochim. Acta, 2013, 106, 91-100.

10 A. Omosebi, X. Gao, J. Landon and K. Liu, ACS Appl. Mater. Interfaces, 2014, 6, 12640-12649.

11 X. Gao, A. Omosebi, J. Landon and K. Liu, J. Electrochem. Soc., 2014, 161, E159-E166.

12 A. Omosebi, X. Gao, J. Rentschler, J. Landon and K. Liu, J. Colloid Interface Sci., 2015, 446, 345-351. 
13 X. Gao, A. Omosebi, J. Landon and K. Liu, Environ. Sci. Technol., 2015, 49, 10920-10926.

14 X. Gao, S. Porada, A. Omosebi, K.-L. Liu, P. M. Biesheuvel and J. Landon, Water Res., 2016, 92, 275-282.

15 P. B. Peters, R. van Roij, M. Z. Bazant and P. M. Biesheuvel, 2016, ArXiv, 1512.04261.

16 D. He, C. E. Wong, W. Tang, P. Kovalsky and T. D. Waite, Environ. Sci. Technol. Lett., 2016, 3, 222-226.

17 T. Kim, J. Yu, C. Kim and J. Yoon, J. Electroanal. Chem., 2016, 776, 101-104.

18 J. Yang, L. Zou, H. Song and Z. Hao, Desalination, 2011, 276, 199-206.

19 M. T. Z. Myint and J. Dutta, Desalination, 2012, 305, 24-30.

20 M.-W. Ryoo, J. H. Kim and G. Seo, J. Colloid Interface Sci., 2003, 264, 414-419.

21 J.-W. Lee, H.-I. Kim, H.-J. Kim and S.-G. Park, Appl. Chem. Eng., 2010, 21, 265-271.

22 C. Kim, J. Lee, S. Kim and J. Yoon, Desalination, 2014, 342, 70-74.

23 J. J. Lado, R. E. Pérez-Roa, J. J. Wouters, M. Isabel TejedorTejedor and M. A. Anderson, Sep. Purif. Technol., 2014, 133, 236-245.

24 S. Brunauer, P. H. Emmett and E. Teller, J. Am. Chem. Soc., 1938, 60, 309-319.

25 G. Y. Gor, M. Thommes, K. A. Cychosz and A. V. Neimark, Carbon, 2012, 50, 1583-1590.

26 M. Aslan, D. Weingarth, P. Herbeck-Engel, I. Grobelsek and V. Presser, J. Power Sources, 2015, 279, 323-333.

27 X. Xu, M. Wang, Y. Liu, T. Lu and L. Pan, J. Mater. Chem. A, 2016, 4, 5467-5473.

28 W. Chen and S. Chen, Angew. Chem., Int. Ed., 2009, 48, 43864389.

29 G. W. Hung and R. H. Dinius, J. Chem. Eng. Data, 1972, 17, 449-451.
30 J. Kestin, H. E. Khalifa and R. J. Correia, J. Phys. Chem. Ref. Data, 1981, 10, 71-88.

31 J. E. Sherwood, F. Stagnitti, M. J. Kokkinn and W. D. Williams, Limnol. Oceanogr., 1991, 36, 235-250.

32 M. Aslan, M. Zeiger, N. Jäckel, I. Grobelsek, D. Weingarth and V. Presser, J. Phys.: Condens. Matter, 2016, 28, 114003.

33 B. Gao, G. Z. Chen and G. Li Puma, Appl. Catal., B, 2009, 89, 503-509.

34 A. C. Ferrari and J. Robertson, Phys. Rev. B: Condens. Matter Mater. Phys., 2001, 64, 075414.

35 S. Fleischmann, N. Jäckel, M. Zeiger, B. Krüner, I. Grobelsek, P. Formanek, S. Choudhury, D. Weingarth and V. Presser, Chem. Mater., 2016, 28, 2802-2813.

36 M. Zeiger, N. Jäckel, V. N. Mochalin and V. Presser, J. Mater. Chem. A, 2016, 4, 3172-3196.

37 F. Beguin, V. Presser, A. Balducci and E. Frackowiak, Adv. Mater., 2014, 26, 2219-2251.

38 Y. Bouhadana, E. Avraham, M. Noked, M. Ben-Tzion, A. Soffer and D. Aurbach, J. Phys. Chem. C, 2011, 115, 16567-16573.

39 X. Sun, P. Song, Y. Zhang, C. Liu, W. Xu and W. Xing, Sci. Rep., 2013, 3, 2505.

40 J. Zhang and L. Dai, ACS Catal., 2015, 5, 7244-7253.

41 R. Zhao, P. M. Biesheuvel, H. Miedema, H. Bruning and A. van der Wal, J. Phys. Chem. Lett., 2009, 1, 205-210.

42 S. Porada, F. Schipper, M. Aslan, M. Antonietti, V. Presser and T.-P. Fellinger, ChemSusChem, 2015, 8, 1867-1874.

43 N. Jäckel, M. Rodner, A. Schreiber, J. Jeongwook, M. Zeiger, M. Aslan, D. Weingarth and V. Presser, J. Power Sources, 2016, 326, 660-671.

44 R.-S. Zhong, Y.-H. Qin, D.-F. Niu, J.-W. Tian, X.-S. Zhang, X.-G. Zhou, S.-G. Sun and W.-K. Yuan, J. Power Sources, 2013, 225, 192-199.

$45 \mathrm{~J}$. Yu, Z. Liu, L. Zhai, T. Huang and J. Han, Int. J. Hydrogen Energy, 2016, 41, 3436-3445. 